\title{
Wajdi Mouawad, Willy Protagoras enfermé dans les toilettes
}

\section{Veronica Cappellari}

\section{Q OpenEdition \\ 1 Journals}

\section{Edizione digitale}

URL: http://journals.openedition.org/studifrancesi/33831

DOI: 10.4000/studifrancesi.33831

ISSN: 2427-5856

\section{Editore}

Rosenberg \& Sellier

\section{Edizione cartacea}

Data di pubblicazione: 1 décembre 2005

Paginazione: 687

ISSN: 0039-2944

\section{Notizia bibliografica digitale}

Veronica Cappellari, «Wajdi Mouawad, Willy Protagoras enfermé dans les toilettes», Studi Francesi

[Online], 147 (XLX | III) | 2005, online dal 30 novembre 2015, consultato il 18 avril 2021. URL: http:// journals.openedition.org/studifrancesi/33831 ; DOI: https://doi.org/10.4000/studifrancesi.33831 


\title{
Wajdi Mouawad, Willy Protagoras enfermé dans les toilettes
}

\author{
Veronica Cappellari
}

\section{NOTIZIA}

WAJDI MOUAWAD, Willy Protagoras enfermé dans les toilettes, Montréal/Arles, Leméac/Actes Sud-Papiers, 2004, pp. 89.

1 Scritta nel 1991 e vincitrice, nel 1998, del Grand Prix dell'Association québécoise des critiques de théâtre di Montréal, la pièce Willy Protagoras enfermé dans les toilettes segna l'esordio letterario dello scrittore e drammaturgo di origine libanese Wajdi Mouawad, emigrato in Québec e ora riconosciuto come uno dei migliori autori del nuovo teatro quebecchese. Formatosi a L'École Nationale de Théâtre du Canada, cofondatore del Théâtre Ô Parleur, direttore artistico del Théâtre de Quat'Sous di Montréal dal 2000 al 2004, Wajdi Mouawad è autore, regista e attore. Gran parte delle sue opere teatrali hanno avuto un grande successo e incontrato il favore della critica in Québec e in Europa, come ad esempio Littoral (Montréal/Arles, Leméac/Actes Sud - Papiers, 1999, vincitrice, nel 2000, del Prix du Gouverneur général), Rêves (Montréal/Arles, Leméac/ Actes Sud - Papiers, 2002) e Incendies (Montréal/Arles, Leméac/Actes Sud - Papiers, 2003).

2 La pièce Willy Protagoras enfermé dans les toilettes, composta da cinque atti ed ambientata all'epoca della guerra civile libanese, raffigura il "delirio" di due famiglie costrette a condividere lo stesso appartamento: i Protagoras e i Philisti-Ralestine. I loro continui litigi accadono sotto gli occhi attenti ed indiscreti degli inquilini dell'intero palazzo che finiscono per esserne coinvolti e si lasciano andare a pettegolezzi, maldicenze e volgarità dal loro balcone simile ad una "gabbia", dove ciascuno vive come un prigioniero. L'intera vicenda ruota però intorno alla figura del diciottenne Willy Protagoras, ragazzo ribelle, pittore naif, analfabeta e un po' bizzarro, il quale, per protestare contro i parenti che si oppongono ad una sua relazione d'amore e per 
vendicarsi degli intrusi che gli invadono l'appartamento, si rinchiude per più di venti giorni nella toilette, impedendone l'uso ai coinquilini. Con questo gesto, Willy vuole denunciare le ingiustizie della società che lo circonda; la sua voce si fa portatrice di un messaggio di libertà e di amore: « Fallait-il nous aimer, oui, nous aimer [...]. La guerre, oui? Oui ? [...] Moi, je vous crie que non! Pas la guerre! Je ne l'aime pas, moi, la guerre. (p. 72) [...] Fallait-il que l'on s'aime» (p. 73). Ma questo auspicio di un futuro migliore, condiviso anche dagli altri giovani protagonisti, è destinato a svanire lentamente: Nelly, sorella di Willy, donna bella, intelligente ed istruita, sceglie, seppur a malincuore, di esiliarsi in un paese ove regna la pace, e in una lettera al fratello spiega come sia più facile parlare della guerra da lontano: «la guerre est plus facile de loin. Ici, tous en parlent, de la guerre. Mais ils ne savent pas de quoi ils parlent, ils font des reportages, des recherches ... Si tu savais à quel point c'est facile de parler de la guerre lorsque partout tu es entouré par la paix» (p. 84). Invece, Abgar Philisti-Ralestine e sua sorella Naïmé (per la quale Willy prova un sentimento d'amore profondo) sono legati da un tragico destino: ormai esausti per la situazione che li circonda, il primo si getta dalla finestra, mentre la seconda si strangola con una corda.

Willy Protagoras enfermé dans les toilettes è stata definita dalla critica una commedia tragica: infatti, se da un lato essa evidenzia i tratti ridicoli e talvolta un po' bizzarri di alcuni suoi personaggi, dall'altro racconta, con tono tragico, i gravi problemi di un Paese, il Libano, per lunghi anni scosso e dilaniato da una guerra violenta e brutale, quella stessa guerra che ancora oggi insanguina il Medio Oriente. Solo l'immensità del mare, ultima immagine offertaci dalla pièce, pare racchiudere in sé un miraggio e schiudere una speranza, una promessa di libertà e di un futuro più sereno. 